\title{
LA MUJER EN LA DIPLOMACIA MEXICANA
}

\author{
Nora RAMÍREZ FLORES*
}

RESUMEN: A lo largo de la historia, la mujer se ha enfrentado a severas barreras legales, culturales, económicas y sociales para poder disfrutar de los mismos derechos y oportunidades que los varones. Hasta hace poco más de 50 años, se otorgó a las mexicanas el derecho al voto. A partir de entonces y gracias al esfuerzo de varias mujeres, las barreras que impiden la equidad de género han venido cayendo poco a poco. Una de las áreas en las que la mujer ha destacado a partir de entonces, es el área diplomática. El presente artículo hace un recuento del camino que han recorrido las mujeres en el Servicio Exterior Mexicano para posicionarse en el primer plano de la carrera diplomática, así como de los cambios más importantes en materia legal durante este proceso.

ABSTRACT: Throughout history womankind has confronted powerful legal, cultural, economic and social barriers in order to enjoy the same rights and opportunities as men. Mexican women were given the right to vote just over 50 years ago. Since then and thanks to the efforts of various women, the obstacles impeding the equality of the sexes have been falling away gradually. One of the areas where women have stood out since then is the diplomatic service. This article recounts the path women have trodden in the Mexican external relations service in order to position themselves in the top stratum of the diplomatic service and also the most important legal changes during that process.

RÉSUMÉ: Au long de l'histoire, la fêmme s'est afronté aux severes barrières légales, cultureles, économiques et sociales dans sa lutte pour la juissance des même droits et oportunités que les hômme. Il y a un peux plus de 50 ans, fut la reconu le droit de vote a la fêmme mexicaine, les barrieres qui empechant l'égalité entre les fêmmes et les hômme disparecerent petit à petit et les fêmmes ont distingués dans le secteur de la diplomacie. Le present article retrace le chemin parcouru par les fêmmes dans les affaires etrangères mexicaines avant d'être au premier plan dans la carrière diplomatique mexicaine ainsi que les les changements légaux durant ce procesus.

* Profesora de derecho internacional público en la Facultad de Derecho de la UNAM. 
No, no temí la pira que me consumiría, sino el cerillo mal prendido y esta ampolla que entorpece la mano con que escribo. Rosario Castellanos*

SUMARIO: I. Introducción. II. La mujer en la administración pública. III. ¿Qué es la diplomacia? Apta o no apta para las mujeres. IV. El Servicio Exterior Mexicano. V. Obstáculos legales para el ingreso de las mujeres al Servicio Exterior Mexicano. La primera barrera. VI. Las diplomáticas mexicanas. VII. Obstáculos culturales y socioeconómicos en la carrera de las diplomáticas. La segunda barrera. VIII. La mujer en la diplomacia mexicana actual. IX. Consideraciones finales.

X. Anexos.

\section{INTRODUCCIÓN}

En la actualidad parece no llamarnos la atención escuchar el nombre de una mujer como directora general de alguna gran compañía. Tampoco suena raro hoy en día hablar de una mujer que tiene el puesto de ministro o es titular de una Secretaría de Estado, o que es científica, catedrática o inclusive jefa de estado y de gobierno. De hecho en nuestros días no hay profesión, puesto o actividad en el que no podamos contar al menos a una mujer destacada en alguna parte del mundo (con excepción del sumo pontificado, en el cual la madre Teresa de Calcuta hubiera hecho un magnífico papel). Mujeres como Golda Meier, Indira Ghandi, Violeta V. de Chamorro y la propia Margaret Thatcher, por citar algunos ejemplos, han sido pruebas fehacientes de que las mujeres pueden desempeñarse en forma exitosa en los encargos públicos más importantes de nuestros países.

Sin embargo, llegar a este estatus ha significado un camino sumamente largo, complicado y muchas veces tortuoso, sobre todo cuando se trata de abrir camino en cada nueva experiencia. Hoy, la tarea no está terminada. Las mujeres siguen enfrentando desventajas respecto a los varones en cuanto al acceso a puestos de mando y a las categorías más altas en la administración pública. Quedan muchos prejuicios por romper y

* Embajadora de México ante el gobierno de Israel. Falleció en Tel-Aviv en 1974, mientras se desempeñaba como diplomática mexicana. 
muchas barreras legales, culturales, económicas y sociales que hace falta aún superar en materia de equidad de género. ${ }^{1}$

Uno de los ejemplos de las dificultades y retos que las mujeres deben enfrentar para desarrollarse como profesionales en la administración pública, lo tenemos en la carrera diplomática, no sólo en México, sino en el servicio exterior de la mayoría de los países del mundo.

El presente ensayo, sin ser exhaustivo, hace un recuento del camino que las mujeres han logrado abrir en el campo de la administración pública y particularmente en el de la carrera diplomática en México, así como las dificultades socioculturales, legales y políticas que han enfrentado y que aún enfrentan en sus vidas como miembros del servicio exterior. Más adelante hacemos un recuento de la trayectoria de algunas de las diplomáticas más destacadas en nuestro país, para concluir con algunas consideraciones de carácter general sobre el tema.

\section{LA MUJER EN LA ADMINISTRACIÓN PÚBLICA}

Después de una primera etapa en la historia antigua de la humanidad en la que regía el matriarcado, ésta se ha caracterizado por la hegemonía masculina en prácticamente todos los puestos de mando en el mundo, con algunas escasas excepciones que han confirmado esta regla.

Es apenas hasta hace poco más de 50 años, cuando se le concede a la mujer el derecho al voto, ${ }^{2}$ otorgándole jurídicamente la capacidad de ejercer su ciudadanía plena. Sin embargo, este reconocimiento legal de sus derechos políticos no eliminó de un plumazo las desventajas culturales, sociales y económicas a las que estamos sujetas, y por supuesto, no impidió que en México y en otros países del mundo nos convirtiéramos, sí en ciudadanas, pero en ciudadanas de segunda categoría.

Sólo por dar un ejemplo y a sabiendas de que la distribución del ingreso en México es sumamente inequitativa, mencionaremos que el $84 \%$

1 La Ley del Instituto Nacional de las Mujeres, define en su artículo 5o. a la "Equidad de Género" como el concepto que refiere al principio conforme al cual hombres y mujeres acceden con justicia e igualdad al uso, control y beneficios de los bienes y servicios de la sociedad, incluyendo aquellos socialmente valorados, oportunidades y recompensas, con la finalidad de lograr la participación equitativa de las mujeres en la toma de decisiones en todos los ámbitos de la vida social, económica, política, cultural y familiar.

2 Se reconoce el 17 de octubre de 1953 como la fecha en que se concede a la mujer mexicana el derecho al voto, al aprobarse la reforma al artículo 34 de la Constitución Política de los Estados Unidos Mexicanos. 
de las mujeres trabajadoras perciben entre 0 y 5 salarios mínimos, es decir entre 0 y 227 pesos diarios aproximadamente. Del 10\% que rebasan este límite, únicamente 257 mil mujeres obtienen más de 10 salarios mínimos. ${ }^{3}$

A pesar de estas y otras desventajas, la mujer ha insistido en abrirse espacios en las diferentes esferas laborales y de la administración pública que habían sido tradicionalmente ocupadas por varones. Gracias a este esfuerzo, es en fechas relativamente recientes que los puestos de mando superior están siendo ocupados por mujeres.

A pesar de que se han dado avances considerables en los años recientes, la presencia femenina en la administración pública y en la política no reflejan todavía la misma proporción en que se divide la población del país, es decir, alrededor del 50\%. Así, por ejemplo, derivado de las elecciones del 2000, solamente 80 diputaciones de un total de 500 fueron ocupadas por mujeres (16\%), mientras que de 128 puestos en el Senado, 20 son ocupadas por personas del sexo femenino (también 16\%). Por lo que respecta al Poder Ejecutivo o propiamente dicho, la administración pública federal, el más alto nivel que ha alcanzado una mujer es el de secretaria de Estado. La primera titular de una secretaría fue Rosa Luz Alegría, nombrada en el sexenio de José López Portillo (1976-82). A partir de entonces, sólo ocho mujeres más han ocupado ese cargo. Tres de ellas en la Secretaría de Turismo y el resto en despachos que no se consideran de primer nivel (como Gobernación o Hacienda), con la extraordinaria excepción de la Secretaría de Relaciones Exteriores (SRE), ocupada por Rosario Green de 1998 al 2000. Actualmente existe sólo una mujer con nivel de secretaria de Estado, Josefina Vázquez Mota, titular de la Secretaría de Desarrollo Social (véase tabla 1 en la siguiente página).

Durante la presente administración se han destacado otras mujeres en puestos de gran importancia. Entre ellas podemos citar entre otras a:

- Margarita Luna Ramos, quien fungió como Consejera Jurídica del Ejecutivo federal y a partir de marzo de 2004 fue nombrada ministro de la Suprema Corte de Justicia de la Nación.

- Xóchitl Gálvez, titular del Consejo para el Desarrollo de los Pueblos Indígenas. 
Tabla 1. Mujeres que han ocupado puestos de secretarias de Estado

\begin{tabular}{|l|l|}
\hline Rosa Luz Alegría & Secretaría de Turismo (1976-1982) \\
\hline Ma. de los Ángeles Moreno & Secretaría de Pesca (1988-1994) \\
\hline María Elena Vázquez Nava & Contraloría General de la Federación (1988-1994) \\
\hline Silvia Hernández Enríquez & Secretaría de Turismo (1994-1997) \\
\hline Julia Carabias Lilo & Secretaría del Medio Ambiente, Recursos Naturales y Pesca (1994-1997) \\
\hline Rosario Green Macías & Secretaría de Relaciones Exteriores (1998-2000) \\
\hline Leticia Navarro Ochoa & Secretaría de Turismo (2000-2003) \\
\hline María Teresa Herrera Tello & Secretaría de la Reforma Agraria (2000-2002) \\
\hline Josefina Vázquez Mota & Secretaría de Desarrollo Social (actual) \\
\hline
\end{tabular}


- Sari Bermúdez, titular del Consejo Nacional para la Cultura y las Artes.

- Laura Valdés, quien fungiera como directora general de la Lotería Nacional para la Asistencia Pública y que fuera separada de su cargo a la mitad de esta administración.

El número de mujeres que ocupan puestos de mando en la administración pública federal ha registrado un avance importante, pero este avance no ha sido constante ni homogéneo. En 1992 había 79 mujeres en puestos de mando superior en el Poder Ejecutivo federal. Las secretarías que más directoras generales, subsecretarias y mujeres con puestos de mando superior tenían en ese año, eran la de Relaciones Exteriores (con ocho funcionarias, incluyendo una subsecretaria y tres embajadoras; véase anexo 1); la de Educación Pública (con siete funcionarias de mando superior) y la oficina de la Presidencia de la República (con seis funcionarias con nivel homólogo al de director general). ${ }^{4}$

De acuerdo con datos recolectados por el Instituto Nacional de las Mujeres (Inmujeres), para 1998, el número de funcionarias con puestos de mando medio y superior en la administración pública federal era de 14,534 , es decir, durante ese año el $27 \%$ de los funcionarios públicos eran del sexo femenino. De este total, 458 mujeres ocupaban puestos de mando superior, ${ }^{5}$ incluyendo dos secretarías de Estado. Ello significa que las mujeres ocupaban menos del $15 \%$ del total de puestos de mando superior. ${ }^{6}$

Para 2003 el número de funcionarias públicas se había incrementado a 16,800. Sin embargo, a pesar de este incremento en el número de mujeres en el servicio público, la proporción respecto al número total de funcionarios públicos disminuyó, pasando del 27\% registrado en 1998 a $23.1 \%$, es decir, cuatro puntos porcentuales menos. Los datos anteriores

4 Fernández P., Anna (comp.), Las mujeres en México al final de sexenio, México, Colegio de México, 1995.

5 Los puestos de mando medio en la administración pública federal se consideran en orden ascendente: jefe de Departamento; subdirector de Área; director de Área; asesor; auditor adjunto o director general adjunto. Los puestos de mando superior que se consideraban en 1998 son: director general, coordinador general, oficial mayor, subsecretario y secretario; así como sus respectivos puestos homólogos. Actualmente se ha insertado el puesto de jefe de unidad entre el coordinador general y el de oficial mayor.

6 Instituto Nacional de las Mujeres, Las mujeres en la toma de decisiones, México, Secretaría de Gobernación, 1999. 
nos dan pie a señalar al menos dos conclusiones. Primera: considerando la información de que disponemos, de 1998 (administración del doctor Ernesto Zedillo) a 2003 (administración del licenciado Vicente Fox) se han creado (o al menos se reportan) alrededor de 19 mil nuevas plazas de mando medio y superior en el Ejecutivo federal; segunda, el "gobierno del cambio" ha preferido contratar varones en los puestos de mando medio y particularmente en los de mando superior, ya que de las 920 nuevas plazas reportadas con nivel de director general o superiores, solamente el $11 \%$ fueron ocupadas por mujeres. Se observa además una disminución substancial en el número de directoras generales y coordinadoras generales entre ambos años. En la tabla 2 y en la gráfica (pueden verse en las siguientes páginas) se presentan datos sobre la distribución de los funcionarios públicos, por puesto y género en los dos años señalados.

Para finalizar esta sección solamente señalaremos que la secretaría que tenía un mayor porcentaje de funcionarias durante el 2003 era la SRE, con el $43 \%$ de su personal de mando. Las secretarías que tienen la menor proporción de mujeres en puestos de mando son la Secretaría de la Defensa Nacional y la Secretaría de Marina, ambas con tan sólo el $6 \%$ (véase anexo 2).

\section{III. ¿QUÉ ES LA DIPLOMACIA? APTA O NO APTA PARA LAS MUJERES}

Hablar hoy en día de diplomacia y diplomáticos está muy lejos de aquel concepto tradicional de la Italia renacentista, en el que se nombraba a representantes embajadores para mantener las buenas relaciones con otras naciones, llevando a cabo los "buenos oficios", a través de muy diversos métodos, para salvaguardar los intereses nacionales. Nombrar embajadores era indispensable en virtud de la imposibilidad de los monarcas y jefes de Estado de trasladarse a muy diversos lugares en la geografía del mundo. Reyes y gobernantes escogían para estas tareas a sus hombres de confianza, cultos y refinados, que pudieran representar dignamente a su patria. Estos hombres deberían tener al mismo tiempo la suficiente agudeza e ingenio para enterarse de los asuntos del Estado receptor, ser el "gran informador" y adelantar las medidas necesarias en caso de ver afectados los intereses propios. 
Tabla 2. Funcionarios públicos, según puesto y género (1998 y 2003)

\begin{tabular}{|c|c|c|c|c|c|c|c|c|c|c|}
\hline \multirow[t]{3}{*}{ Puesto } & \multicolumn{9}{|c|}{ Número de funcionarios } & \multirow{3}{*}{$\begin{array}{l}\text { \% incorpora- } \\
\text { ción de mujeres } \\
\text { en nuevos } \\
\text { puestos }\end{array}$} \\
\hline & \multicolumn{2}{|c|}{ Total } & \multicolumn{2}{|c|}{ Mujeres } & \multicolumn{2}{|c|}{ Hombres } & \multicolumn{3}{|c|}{$\begin{array}{c}\text { Variación absoluta } \\
(2003-1998)\end{array}$} & \\
\hline & 1998 & 2003 & 1998 & 2003 & 1998 & 2003 & Total & Mujeres & Hombres & \\
\hline Total & 53,835 & 72,575 & 14,534 & 16,799 & 39,301 & 55,776 & 18,740 & 2,265 & 16,475 & 12.1 \\
\hline Subtotal mandos superiores & 3,098 & 4,018 & 458 & 559 & 2,640 & 3,459 & 920 & 101 & 819 & 11.0 \\
\hline Secretario y homólogos & 22 & 42 & 2 & 4 & 20 & 38 & 20 & 2 & 18 & 10.0 \\
\hline Subsecretario y homólogos & 106 & 680 & 5 & 114 & 101 & 566 & 574 & 109 & 465 & 19.0 \\
\hline Oficial mayor y homólogos & 170 & 417 & 18 & 80 & 152 & 337 & 247 & 62 & 185 & 25.1 \\
\hline Coordinador general y homólogos & 464 & 441 & 98 & 46 & 366 & 395 & -23 & -52 & 29 & Desincorporación \\
\hline Director general y homólogos & 2,336 & 2,438 & 335 & 315 & 2,001 & 2,123 & 102 & -20 & 122 & Desincorporación \\
\hline Subtotal mandos medios & 50,737 & 68,557 & 14,076 & 16,240 & 36,661 & 52,317 & 17,820 & 2,164 & 15,656 & \begin{tabular}{|r}
12.1 \\
\end{tabular} \\
\hline Aud., dir. gral. adjunto y homólogos & 1,028 & 557 & 286 & 26 & 742 & 531 & -471 & -260 & -211 & Desincorporación \\
\hline Asesor y homólogos & 1,692 & 2,325 & 509 & 235 & 1,183 & 2,090 & 633 & -274 & 970 & Desincorporación \\
\hline Director de área y homólogos & 6,291 & 11,974 & 1,631 & 3,496 & 4,660 & 8,478 & 5,683 & 1,865 & 3,818 & 32.8 \\
\hline Subdirector y homólogos & 13,827 & 18,830 & 3,289 & 4,602 & 10,538 & 14,228 & 5,003 & 1,313 & 3,690 & 26.2 \\
\hline Jefe de departamento y homólogos & 27,899 & 34,871 & 8,361 & 7,881 & 19,538 & 26,990 & 6,972 & -480 & 7,452 & Desincorporación \\
\hline
\end{tabular}

FUENTE: Elaboración propia con base en datos de Conmujer 1999 e Inmujeres 2003. 
Gráfica. Funcionarios públicos según puesto y género, 1998 y 2003

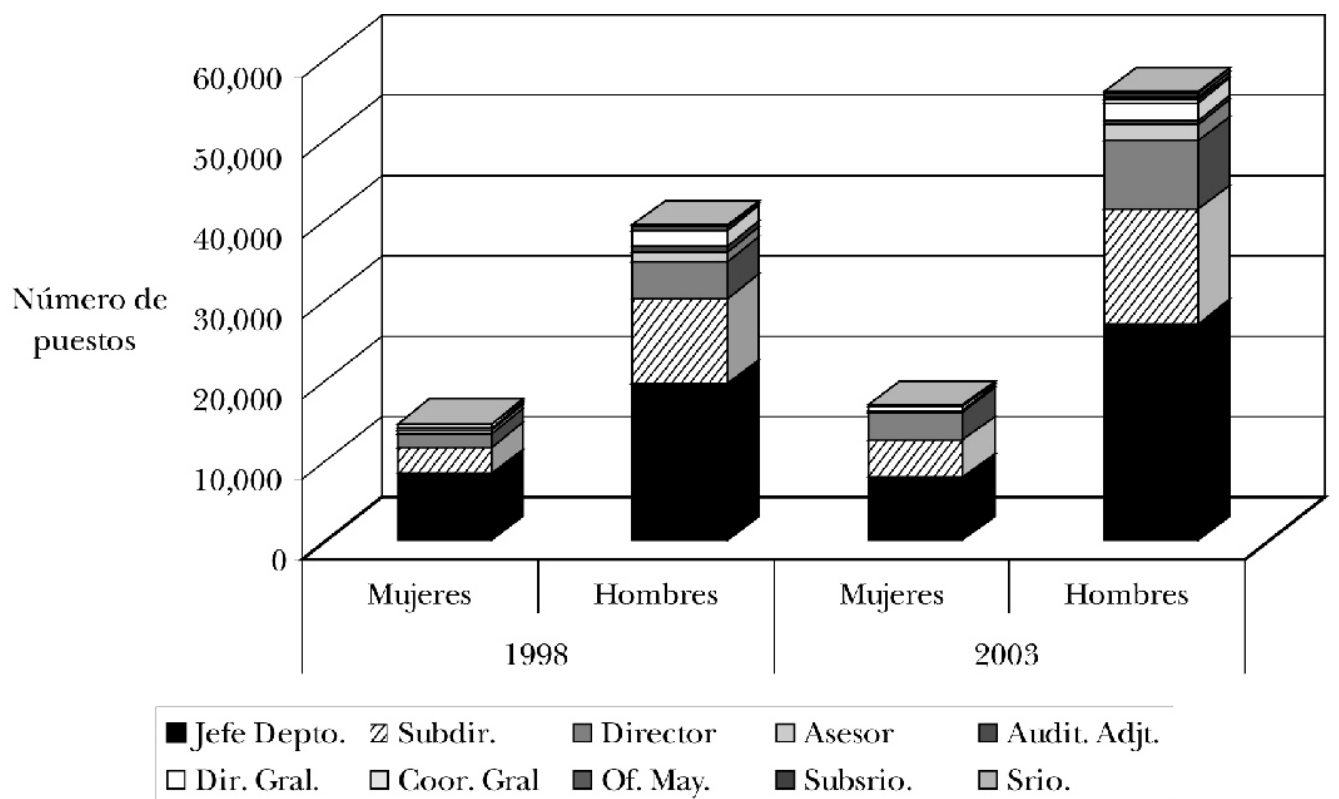


Actualmente los conceptos de diplomacia y de diplomático han evolucionado con el fin de responder a los grandes cambios que vive el mundo actual y al acelerado proceso de globalización, que convierten a las relaciones entre Estados en circunstancia ineludible y cotidiana. Existen muchas y variadas definiciones de diplomacia. Haciendo una compilación de muchas de ellas, podemos definir a la diplomacia actual como el arte de representar al gobierno de un país ante los Estados del mundo y las organizaciones multilaterales, con el fin de preservar los intereses nacionales y fomentar la cooperación, a través de la negociación.

El embajador mexicano Walter Astié señala que en la actualidad la ocupación de diplomático reviste características sui generis, que por lo regular no se dan en ninguna otra profesión. Así, por ejemplo, un diplomático debe contar con la capacidad de adaptarse a vivir en diferentes países del mundo y a sus diversas culturas:

A separarse de las raíces, de la familia, de los amigos, al grado de llegar a sentirse extranjero en la nación propia después de haber vivido durante años en otras tierras. El desempeño cotidiano de la diplomacia es asimismo una tarea que enfrenta una gran variedad de situaciones estresantes: el estricto ceremonial que la caracteriza, sus múltiples reglas protocolarias, las presiones constantes de los encuentros entre altos dignatarios y personalidades, la multitud de actos, ceremonias y eventos a las cuales se debe asistir, las prisas y noches en vela que por lo general acompañan a las conferencias internacionales, los largos debates y negociaciones, las innumerables presentaciones públicas, el incesante cabildeo que debe realizarse, las fricciones y roces entre los países que hay que tratar de solucionar, los innumerables convivios sociales que hay que atender - y ofrecer- con una sonrisa en los labios... Asimismo el diplomático puede verse expuesto a episodios de riegos políticos y bélicos, a desastres humanitarios o a situaciones de violencia o penuria. En particular, el cónsul conoce a fondo las dificultades de lidiar con los problemas y dramas de la condición humana. $^{7}$

Ante estas difíciles tareas que afrontar, el diplomático requiere ser un individuo con un perfil muy especial, y que de acuerdo a Nicolson, debe 
contar con las llamadas siete virtudes diplomáticas: veracidad, precisión, calma, buen carácter, paciencia, modestia y lealtad. ${ }^{8}$

Aunque en ninguna de las definiciones de diplomacia que hemos podido consultar, incluyendo las referencias anteriores, se indica que la mujer, por sus características y habilidades, está incapacitada para llevar adelante esta labor, a lo largo de la historia la diplomacia también ha estado dirigida por los varones. Los embajadores, representantes y enviados extraordinarios y plenipotenciarios habían sido generalmente del sexo masculino hasta mediados del siglo pasado. La incorporación de las mujeres en las embajadas y representaciones se había limitado a actividades "propias" del sexo, de acuerdo al modo de pensar de aquellos años. De esta forma, si una mujer era incorporada a las labores diplomáticas, sus tareas se circunscribían a las de taquígrafa, mecanógrafa, archivista y en el mejor de los casos, a las de traductora.

Aunque en nuestros días existen mujeres dentro de los cuerpos diplomáticos de la mayoría de los Estados, en las décadas pasadas se presentaban un sinnúmero de obstáculos de índole legal, cultural, política, económica y social que inhibieron el ingreso de las mujeres a estos cuerpos. En el presente ensayo, nos referiremos en particular a las barreras que las mujeres han tenido de superar para ingresar al Servicio Exterior Mexicano (SEM), así como a los diversos problemas que aún, con el cambio de las leyes, limitan su participación y ascenso en la carrera diplomática.

\section{EL SERVICIO EXTERIOR MEXICANO}

De acuerdo con la ley correspondiente, promulgada en 1994 y reformada en el 2002, el SEM es el cuerpo permanente de funcionarios del Estado, encargado específicamente de representarlo en el extranjero y responsable de ejecutar la política exterior de México, de conformidad con los principios normativos que establece la Constitución Política de los Estados Unidos Mexicanos.

En el artículo segundo de la ley, se señalan las obligaciones del SEM, entre las que se cuentan:

8 Nicolson, H., The Evolution of Diplomatic Metod, Gran Bretaña, Universidad de Leiceser, 1998. 
- Promover y salvaguardar los intereses nacionales ante los Estados extranjeros y en los organismos y reuniones internacionales en los que participe México.

- Proteger, de conformidad con los principios y normas del derecho internacional, la dignidad y los derechos de los mexicanos en el extranjero y ejercer las acciones encaminadas a satisfacer sus legítimas reclamaciones.

- Mantener y fomentar las relaciones entre México y los miembros de la comunidad internacional e intervenir en todos los aspectos de esos vínculos que sean competencia del Estado.

- Intervenir en la celebración de tratados.

- Cuidar el cumplimiento de los tratados de los que México sea parte y de las obligaciones internacionales que correspondan.

- Velar por el prestigio del país en el exterior.

- Promover el conocimiento de la cultura nacional en el exterior y ampliar la presencia de México en el mundo.

- Recabar en el extranjero la información que pueda ser de interés para México, y difundir en el exterior información que contribuya a un mejor conocimiento de la realidad nacional.

- Coadyuvar a la mejor inserción económica de los México en el mundo.

Para cumplir con estas tareas, el SEM se encuentra organizado en dos ramas:

a) La diplomático-consular, en la que se encuentran los funcionarios. Sus rangos son: agregado diplomático, tercer secretario, segundo secretario, primer secretario, consejero, ministro y embajador.

b) La técnico-administrativa, cuyos miembros desarrollan funciones de apoyo a los funcionarios. Sus rangos son: técnico-administrativo C, B y A; agregado administrativo C, B y A y coordinador administrativo. ${ }^{9}$

9 Anteriormente la rama diplomático-consular estaba dividida en dos. Los nombres de los rangos actuales se tomaron de la rama diplomática, ya que en la rama consular, los rangos en orden ascendente eran los siguientes: vicecónsul, cónsul de 4a.; cónsul de $3 \mathrm{a}$., cónsul de $2 \mathrm{a}$., cónsul de $1 \mathrm{a}$. y cónsul general. Por su parte, los rangos de la rama técnico-administrativa también variaron. Anteriormente eran denominados como agregado administrativo de 1a., 2a. y 3a., y canciller de 1a., 2a. y 3a. El puesto de canciller era el más bajo y paradójicamente podía ser confundido con el cargo del titular de la cancillería, es decir, el Secretario de Relaciones Exteriores. 


\section{OBSTÁCULOS LEGALES PARA EL INGRESO \\ DE LAS MUJERES AL SERVICIO EXTERIOR MEXICANO. LA PRIMERA BARRERA}

La Ley del Servicio Exterior Mexicano vigente, y de la que hemos hecho referencia, no hace distinción alguna en materia de género respecto a las disposiciones correspondientes al ingreso, ascensos, obligaciones, derechos, prestaciones o sanciones en la carrera diplomática en cualquiera de las dos ramas. Sin embargo, esta igualdad jurídica no existía en las legislaciones de los años anteriores. A pesar de que la mujer obtuvo sus derechos como ciudadana en 1953, es hasta 1967 cuando se llevan a cabo las modificaciones necesarias en el marco jurídico respectivo para la plena incorporación de las mujeres al SEM.

Hagamos un rápido recuento de las disposiciones jurídicas que han acompañado al SEM a lo largo de su historia y los obstáculos para el ingreso femenino.

- Durante el siglo XIX, la legislación que normaba a los cuerpos diplomáticos y consulares del México Independiente negaban a la mujer la posibilidad de representar al país en el extranjero. Sin embargo, los mismos preceptos permitían que los puestos de menor rango en el extranjero, como vicecónsules y agregados, pudieran ser ocupados por personas de nacionalidad diferente a la mexicana.

- La Ley del Servicio Consular Mexicano de 1923 señalaba que las mujeres sólo podrían prestar sus servicios como "empleadas", es decir, como escribientes, intérpretes y traductoras.

- Por su parte, la Ley del Servicio Exterior Orgánica de los Cuerpos Diplomático y Consular Mexicanos, así como su reglamento, promulgados ambos en 1943, no hacían una exclusión específica del ingreso de las mujeres a estos cuerpos. Pero de manera implícita señalaba que uno de los requisitos de ingreso era "el ser soltero o estar casado con mujer mexicana de origen". Por otro lado, se prohibía a los miembros del servicio contraer matrimonio con mujer extranjera, o que no fuera mexicana de origen. Y si ello no era suficiente, el Reglamento de 1934 establecía como uno de los requisitos para ingresar como funcionario al Servicio Exterior de Carrera, el ser mexicano por nacimiento, en pleno goce de sus derechos civiles y políticos. Recordemos que fue hasta 1953 cuando 
se otorgó a las mujeres el derecho al voto, por lo que ninguna mujer contaba en esos momentos con el pleno goce de sus derechos civiles y políticos. ${ }^{10}$

- De acuerdo a los registros que conserva la SRE, las enmiendas hechas al reglamento entre 1940 y 1955 permitieron el ingreso limitado de las mujeres a la carrera diplomática. Es entonces que surgen las primeras funcionarias, mientras que algunas mujeres más fueron nombradas para ocupar puestos consulares en el extranjero. Es hasta 1967 que la mayoría de los obstáculos jurídicos que impedían el ingreso pleno de las mujeres al SEM, fueron superados.

- Durante la década de los setenta se llevaron a cabo más ingresos de mujeres como funcionarias de carrera dentro del servicio. A pesar de ello, esta situación todavía no era una práctica común. ${ }^{11}$

- La Ley Orgánica del SEM, promulgada en 1982 y su reglamento, otorgan ya explícitamente a la mujer la oportunidad de ingresar al SEM, permitiendo su desarrollo, promoción y ascenso en igualdad jurídica con el varón. Sin embargo, el reglamento de esta ley todavía señalaba en su artículo 6o., que cuando ambos cónyuges pertenecían al servicio, éstos no podían ser comisionados en una misma misión diplomática o consular. Ello significaba que la mayoría de las veces, la mujer que estaba casada con un miembro del SEM, generalmente con un rango mayor al de ella, se viera obligada a suspender provisional o definitivamente su carrera.

- La ley en vigor ofrece una salida a la disyuntiva anterior en el artículo 98 de su reglamento:

En el caso de cónyuges miembros de carrera del Servicio Exterior, la Comisión de Personal podrá adscribirlos a la Secretaría, a ciudades donde existan dos o más representaciones de México, o en adscripciones que se encuentren a una distancia razonable la una de la otra. La Comisión de Personal también podrá adscribir cónyuges que sean miembros del Servicio Exterior a la misma representación, siempre y cuando: I. Se trate de una oficina con más de 10 miembros de la rama diplomático-consular en su plantilla de personal, y no exista subordinación directa de un cónyuge

10 González Martínez, Aída, "La mujer en el Servicio Exterior Mexicano", en varios autores, El Servicio Exterior Mexicano, México, Instituto Matías Romero, SRE, 1987.

11 Idem. 
al otro, de tal suerte que no se trastorne la buena marcha de la misma, y II. El Titular esté de acuerdo. ${ }^{12}$

\section{LAS DIPLOMÁTICAS MEXICANAS}

A pesar de los impedimentos jurídicos que se han reseñado líneas arriba, en la década de los cuarenta y cincuenta, algunas mujeres ingresaron en la vida diplomática y, como era de esperarse, pocos años después brillaron en ella.

La primera mujer a la que se le asignó un alto rango en el servicio diplomático fue a la profesora Palma Guillén de Nicolau, a quien se nombró enviado extraordinario y ministro plenipotenciario de México ante el gobierno de Colombia, en la década de los años cuarenta. ${ }^{13}$

La primera mujer que fue nombrada embajadora del gobierno de México, fue la maestra, Amalia Caballero de Castillo Ledón, embajadora ante el gobierno de Suiza en 1956-5714 y más tarde embajadora ante el gobierno de Austria en 1964. La maestra Caballero fue también subsecretaria de Asuntos Culturales en la Secretaría de Educación en 1959.

Otros dos ejemplos notables hacia la mitad del siglo pasado fueron la doctora en ciencias de la educación, Paula Alegría, y la licenciada en derecho, María Emilia Téllez. En 1946, la doctora Alegría tuvo su primer nombramiento en el SEM, y en 1962 logró ser la primera embajadora de carrera. Durante su trayectoria recibió del gobierno de Dinamarca la orden Darenborg en el grado de la Gran Cruz, otorgada para reconocer la labor diplomática extraordinaria con la Casa Real Danesa. ${ }^{15}$ Por su parte, la licenciada Téllez inició su carrera en 1947, escalando uno a uno todos los niveles de la carrera. Después de desempeñar diversos cargos, entre ellos el de directora general de Organismos Internacionales (1964-70), llegó a ser la primera mujer que ocupó en la SRE el más alto cargo admi-

12 SRE, Ley del Servicio Exterior Mexicano, 1994 y Reglamento de la Ley del Servicio Exterior Mexicano, enero de 2002.

13 La embajadora Aída González hace referencia a la profesora Palma Guillén como ministro extraordinario y plenipotenciario, pero durante la década de los cincuenta. Véase González, op. cit., nota 10 .

14 Ruiz Olvera, Estela, La Mujer y la Diplomacia, México, UNAM, Escuela Nacional de Ciencias Políticas y Sociales, 1963, tesis para obtener el grado de licenciada en ciencias diplomáticas.

15 Paula Alegría murió en marzo de 1970, tras haber permanecido en coma durante cuatro años a raíz de un derrame cerebral que la sorprendió desempeñándose como embajadora de México en Dinamarca en 1966. Hoy, una escuela primaria del D. F. lleva su nombre. 
nistrativo, oficial mayor (1970-1976). También llegó a ocupar el puesto de subsecretaria de la SRE. ${ }^{16}$

Después de que estas grandes señoras abrieron brecha en un mundo preponderantemente masculino, más mujeres decidieron seguir sus pasos, terminando de allanar el camino legal para su incorporación plena al servicio. Actualmente existe un buen número de mujeres como miembros del SEM. Pero la mayoría de ellas se encuentran en la rama técnico-administrativa. Siguen siendo pocas las funcionarias con altos rangos diplomáticos. A finales del 2004, solamente 12 mujeres tenían el rango de embajadoras.

Para ilustrar este procedimiento, lento y lleno de complicaciones, a continuación decidimos incluir algunos datos sobre el proceso de incorporación de las mujeres al SEM, así como información sobre el número de funcionarias de carrera en la historia de la SRE.

Concursos públicos de ingreso al SEM:

- En el concurso público de ingreso al SEM de 1947 se presentaron solamente tres mujeres (una de ellas, Emilia Téllez, de quién ya hicimos referencia). Siete años más tarde, en 1954, participaron siete mujeres.

- Entre 1971 y 1975 se efectuaron seis concursos públicos en los que se registraron 384 hombres y 182 mujeres. De éstos solamente ingresaron 21 mujeres y 76 varones. ${ }^{17}$

- En los concursos de ingreso celebrados en 1980, 1981 y 1982, se inscribieron 54, 67 y 80 mujeres, respectivamente. 15 años después, en 1997, 98 y 99, se inscribieron 277, 225 y 520 mujeres, respectivamente. ${ }^{18}$

- En 1999 el número de mujeres inscritas para el concurso superó al de los hombres (520 mujeres por 496 hombres).

- A pesar del notable incremento en el número de mujeres inscritas para el concurso, las estadísticas muestran que los exámenes de admisión a la rama diplomático-consular fueron aprobados principalmente por los varones, por lo que el número de funcionarias de carrera sigue siendo muy bajo.

18 Astié-Burgos, Walter, op. cit., nota 7, pp. 10 y 11. 
Mujeres miembros del SEM:

- Entre 1953 y 1975, el SEM casi duplicó el número de sus integrantes al pasar de 478 a 844 .

- De los 478 miembros en 1953, solamente 102 eran mujeres, 12 de ellas eran funcionarias y 90 cancilleres o personal de apoyo. En 1975, de los 844 miembros, 320 eran mujeres, 91 con rango de funcionario y 229 cancilleres.

- En 1953, solamente el $4.8 \%$ de los funcionarios eran mujeres. Para 1975, este porcentaje aumentó al 20\%.

- Entre 1980 y 1999 ingresaron al SEM 578 miembros, de los cuales 146 eran mujeres, es decir, el 25\%.

- Los datos más recientes de que disponemos (2002), indican que existen 453 mujeres en el SEM en ambas ramas, 184 son funcionarias, lo que equivale al $26 \%$ de los funcionarios de carrera del SEM. Por lo que respecta a la rama técnico-administrativa, el 64\% del personal es del sexo femenino (269). Actualmente existen 12 embajadoras de carrera vs. 52 embajadores (véase tabla 3 en la próxima página).

Como se observa, el número de mujeres que ingresan al SEM va en aumento, y poco a poco el porcentaje de funcionarias es mayor. Sin embargo, este proceso ha sido sumamente lento. Ha tomado medio siglo que las mujeres ocupen una cuarta parte de los puestos con rango de funcionario en el SEM.

\section{OBSTÁCULOS CULTURALES Y SOCIOECONÓMICOS EN LA CARRERA DE LAS DIPLOMÁTICAS. LA SEGUNDA BARRERA}

Una vez superadas las trabas de índole legal para que las mujeres pudieran competir en igualdad de condiciones para ingresar en el SEM y hacer carrera en él, es importante señalar otro tipo de aspectos que han determinado e influyen aún en el desarrollo de las mujeres dentro de los cuerpos diplomáticos.

Esos aspectos, que frenan las carreras diplomáticas de las mujeres, incluyen factores de orden económico, cultural y social que aún no es 
Tabla 3. Personal de carrera del Servicio Exterior Mexicano, 2002. Rama diplomático-consular.

\begin{tabular}{|c|c|c|c|c|c|}
\hline Categoría & Mujeres & Hombres & Total & \multicolumn{2}{|c|}{ Participación porcentual } \\
\hline & & & & Mujeres & Hombres \\
\hline Embajador emérito & 0 & 1 & 1 & $0 \%$ & $100 \%$ \\
\hline Embajador eminente & $1 *$ & 3 & 3 & $25 \%$ & $100 \%$ \\
\hline Embajador & 12 & 52 & 64 & $19 \%$ & $81 \%$ \\
\hline Ministro & 26 & 95 & 121 & $21 \%$ & $79 \%$ \\
\hline Consejero & 26 & 78 & 104 & $25 \%$ & $75 \%$ \\
\hline Primer secretario & 28 & 87 & 115 & $24 \%$ & $76 \%$ \\
\hline Segundo secretario & 34 & 100 & 134 & $25 \%$ & $75 \%$ \\
\hline Tercer secretario & 54 & 87 & 141 & $38 \%$ & $62 \%$ \\
\hline Agregado diplomático & 3 & 9 & 12 & $25 \%$ & $75 \%$ \\
\hline
\end{tabular}

* Actualmente hay dos embajadoras eminentes.

FUENTE: Elaboración propia con datos del Servicio Exterior Mexicano, SRE. 
posible superar en la sociedad mexicana y en muchos otros países, sobre todo en los menos desarrollados.

Una de las primeras desventajas que enfrentan las mujeres se encuentra en la formación profesional. Para ingresar al SEM, es necesario contar al menos con una licenciatura. De acuerdo a las estadísticas de las diferentes instituciones de educación superior, aunque el ingreso a estudios profesionales mantiene un porcentaje similar de mujeres y hombres, son muchas más las mujeres que no concluyen sus estudios, ya que están sujetas a diversas presiones sociales y culturales.

Otro de los factores importantes a señalar se refiere al ámbito sociocultural. La sociedad mexicana tradicionalmente ha tratado de restringir el campo de acción femenino a ocupaciones "propias del sexo". Cuando las mujeres logran desarrollarse como profesionistas, pareciera ser que su estado civil les marca un límite, ligando nuevamente su destino profesional a las decisiones y necesidades de su esposo y/o hijos:

La mujer casada o madre de familia, y principalmente la mujer de las ramas diplomática-consular enfrenta dificultades mayores para conciliar su desarrollo profesional como esposa y como madre. Ello ha derivado en que sean contadas las que en esta situación ingresan o permanecen por largo tiempo en el Servicio, dado que una de las características del desempeño profesional de sus miembros consiste en residir en el extranjero y, supuestamente, cambiar periódicamente de adscripción. ${ }^{19}$

Por esta razón la mujer se ve en muchas ocasiones en la disyuntiva de escoger entre su familia y su carrera diplomática. Son, en efecto, pocos los hombres que deciden abandonar su vida, sus trabajos o sus negocios en el país, a fin de seguir a su esposa y permanecer en el extranjero como dependientes económicos de ella y ser la "segunda parte de la pareja”. Adicionalmente, la Convención de Viena sobre Relaciones Diplomáticas de 1961 y la normatividad específica de la mayoría de las naciones, prohíbe trabajar en el país receptor a los cónyuges de los diplomáticos extranjeros.

Por otro lado, las mujeres miembros del SEM que en el ejercicio de sus funciones en el extranjero contraen matrimonio, previa autorización de la SRE, con nacionales de otros países, suelen también enfrentar la disyuntiva de permanecer con su familia o seguir su carrera en el mo- 
mento en que enfrentan una orden de traslado, ya que los patrones socioculturales mencionados las "obligan a seguir a su pareja".

Otros elementos de desventaja que enfrentan las mujeres del SEM se refieren a las prestaciones económicas y en materia de seguridad social para su pareja. Se ha dado el caso que en varias ocasiones la SRE, suponemos que por razones de presupuesto, niega el pago de pasajes por traslado o por vacaciones del cónyuge varón, argumentando que al no tratarse de un "dependiente económico directo", no se justifica la erogación, siendo que la Ley del SEM y su reglamento tipifican esta prestación en forma explícita. Por otro lado, y en materia de seguridad social, los beneficios que otorga el ISSSTE a las mujeres trabajadoras, tratándose de diplomáticas o no, sólo se extiende al cónyuge varón en el caso de que éste sea mayor de 55 años o esté incapacitado física o mentalmente. Paradójicamente, en el caso de que el asegurado sea un hombre, el servicio se extiende a su esposa o inclusive a su concubina sin mayor restricción.

Las últimas referencias que haremos aquí sobre los problemas que limitan el desarrollo de una mujer en su carrera como diplomática se refieren a aspectos culturales e inclusive religiosos. Existen varios países musulmanes y del oriente medio en los cuales es prácticamente imposible enviar a una mujer con la representación del Estado mexicano, ya que su cultura, religión o ideología le niegan de entrada la facultad de desempeñarse en tareas diferentes a las de mujer de casa, esposa y cuidadora de hijos.

Finalmente, cuando una mujer, a pesar de todos los obstáculos logra alcanzar rangos de ministra o embajadora, debe enfrentar actitudes de descalificación y discriminación en muchas de las negociaciones internacionales que le son asignadas, dependiendo de la cultura e idiosincrasia de la contraparte.

La embajadora emérita, Aída González, resume esta situación haciendo referencia a una frase que, de acuerdo con su experiencia, todas las mujeres del SEM que han participado en reuniones internacionales reconocen: "Rara combinación: además de inteligente es elegante y bonita". Este tipo de expresiones, señala la embajadora, inhiben a las funcionarias en su desempeño profesional, o bien provocan reacciones que pueden alterar los resultados planeados de la negociación, inclusive cortando el diálogo. 


\section{LA MUJER EN LA DIPLOMACIA MEXICANA ACTUAL}

Como hemos podido observar, cada vez hay un mayor número de mujeres que pueden ocupar rangos más altos dentro del SEM. Son asimismo más los ejemplos de mujeres sobresalientes en el ámbito diplomático. Es por ello que hemos decidido reservar la última sección del ensayo para hacer referencia a cuatro mujeres que han destacado notablemente en el mundo de la relaciones internacionales y la diplomacia. Nos referimos a la embajadora Olga Pellicer Silva, a la embajadora eminente Carmen Moreno Toscano, a la embajadora eminente Aída González Martínez y a la embajadora Rosario Green Macías. El hecho de que hayamos elegido solamente a estas cuatro mujeres ejemplares, no quiere decir que sean las únicas diplomáticas de quien podamos decir algo interesante, más bien tenemos espacio limitado.

Iniciaremos reseñando la trayectoria de la embajadora Olga Pellicer Silva, que sin ser miembro de carrera del SEM, ha tenido un desempeño diplomático muy sobresaliente. Fue miembro de la Comisión Consultiva de Política Exterior, directora general para el Sistema de Naciones Unidas, representante alterna de México ante la ONU, embajadora en Grecia y en Austria, directora general del Instituto Matías Romero de Estudios Diplomáticos, y posteriormente coordinadora general del instituto cuando a éste se la agregaron las responsabilidades del Acervo Histórico-Diplomático y de la Unidad de Investigación y Prospectiva Internacionales, quedando su puesto con un nivel de subsecretaria. Fue también representante de México ante el Organismo Internacional de la Energía Atómica, en el cual participó activamente en el impulso de la nueva agenda del desarme.

La embajadora Carmen Moreno Toscano ha tenido una trayectoria sobresaliente en la vida diplomática de México. Como parte de su carrera dentro de la SRE, fue embajadora de México ante los gobiernos de Costa Rica y de Guatemala. En este último país fue condecorada por el presidente Alfonso Portillo con la Orden del Quetzal en el grado de Gran Cruz. Tuvo una amplia experiencia en el ámbito multilateral, representando a nuestro país en diversos foros y negociaciones. Destaca su papel como representante permanente de México ante la Organización de Estados Americanos. Fue también subsecretaria de Relaciones Exteriores para África y Medio Oriente durante la administración de Rosario Green. Ostenta el honroso y codiciado título de embajadora eminente. Aunque 
se retiró del SEM durante la presente administración para coordinar el Programa de Prevención de Conflictos y Negociación en el Centro de Investigaciones Interdisciplinarias en Ciencias Sociales y Humanidades en la UNAM; fue nombrada por el secretario general de la ONU, Kofi Annan, directora del Instituto Internacional de Investigaciones y Capacitación para la Promoción de la Mujer (Instraw) de la propia Organización de las Naciones Unidas. En dicho instituto ha puesto en marcha un programa de trabajo en apoyo a la creación de estadísticas diferenciadas por género.

Merece una mención especial la embajadora Aída González Martínez, quién además de representar en forma destacada a México en diversos países y foros internacionales, particularmente de la ONU, ha sido oficial mayor en la cancillería, desempeñando una carrera diplomática que podría servir de modelo a las nuevas generaciones de funcionarias del SEM. Ostenta además el honorable cargo de embajadora eminente, y a lo largo de su trayectoria ha apoyado las acciones tendientes a procurar la igualdad de géneros dentro y fuera de la diplomacia. La embajadora González es referencia obligada cuando en el ámbito internacional se tratan los temas sociales, humanitarios, y en particular, los derechos humanos de mujeres y niños.

Finalmente hablaremos un poco de la embajadora Rosario Green Macías, quien representa, desde nuestro particular punto de vista, el ejemplo más completo del trabajo constante y eficiente de una mujer dentro de la administración pública y dentro de la diplomacia.

A pesar su amplia trayectoria en la cancillería, y de que fue directora del Instituto Matías Romero de Estudios Diplomáticos, nunca ingresó al Servicio Exterior de Carrera. Sin embargo, sus méritos y trabajo le valieron ganarse los más altos puestos en la diplomacia nacional y en los organismos multilaterales.

Rosario Green estudió la Licenciatura en Relaciones Internacionales de la Universidad Nacional Autónoma de México; cuenta con una Maestría en Economía en El Colegio de México y con una segunda Maestría en Economía cursada en la Universidad de Columbia (Nueva York). En 1996 recibió un Doctorado Honoris Causa en Ciencias Humanísticas de la Universidad New Rochelle (Nueva York), y en 1999 un Doctorado Honoris Causa en Derecho de la Universidad Tufts de Massachussets. Antes de ocupar diversos cargos en la SRE y en Naciones Unidas, fue 
profesora e investigadora en la UNAM y El Colegio de México, y autora de varios libros y artículos sobre economía y relaciones internacionales.

Rosario Green fue también representante de México ante el Banco Mundial y funcionaria de la misión de México ante los organismos internacionales con sede en Ginebra. Asimismo, fue secretaria ejecutiva de la Comisión Nacional de Derechos Humanos y secretaria de la Comisión de Asuntos Internacionales del PRI. Como ya mencionamos, fue también directora del Instituto Matías Romero de Estudios Diplomáticos de la SRE, y secretaria ejecutiva de la Comisión sobre el Futuro de las Relaciones México-Estados Unidos de la Fundación Ford. Rosario Green fue la última embajadora de México ante el gobierno de la República Democrática Alemana y se desempeñó también como subsecretaria de Relaciones Exteriores para América Latina, Cooperación Internacional y Asuntos Culturales, y subsecretaria general adjunta para Asuntos Políticos de la ONU. Entre 1997 y 1998, fue presidente nacional de la Fundación Colosio, AC.

La embajadora Green se desempeñó también como consultora de diversos organismos internacionales. Fungió como asesora especial del secretario general de las Naciones Unidas, y de 1994 a 1997, a invitación expresa del secretario general, se convirtió en la subsecretaria general de ese organismo. De hecho, Rosario Green fue la primera mujer en haber desempeñado un cargo de tal jerarquía en las Naciones Unidas.

Fue senadora de la república para el periodo 1997-2000, cargo al que pidió licencia para desempeñarse como secretaria de Relaciones Exteriores entre 1998 y 2000, siendo la primera y única mujer que ha estado al frente de esta dependencia. Una vez concluida su gestión al frente de la cancillería, fue nombrada embajadora de México ante el gobierno de Argentina, cargo que desempeñó hasta 2004.

Como podemos darnos cuenta, parece ser que no hay cargo que no pueda ser ocupado por una mujer tan magnífica como lo es la señora Rosario Green.

Su gestión al frente de la SRE estuvo siempre marcada por el sello de la equidad, incorporando en su grupo de trabajo, tanto a hombres como a mujeres responsables y capaces. Su participación en los foros multilaterales, particularmente en la ONU, así como su trabajo de negociación en reuniones bilaterales fue siempre reconocido y respetado, a tal grado que en los círculos políticos se mencionaba que era la única funcionaria en el mundo que podía sostener una discusión brillante con la 
célebre Madeleine Albright, secretaria de Estado de los Estados Unidos de América.

Al respecto, Rosario Green relató en cierta ocasión una anécdota, haciendo referencia a una conferencia de prensa con Albrigth, después de una reunión bilateral. Uno de los reporteros al solicitar la palabra, indicó: "Esta pregunta es para usted, señora secretaria". Ambas mujeres cruzaron una mirada, y entonces Albright alzó la voz diciendo que esa era la primera vez en su carrera, en que no sabía a quién de las dos personas en la mesa iba dirigida la pregunta, ya que era la única conferencia de prensa en el mundo en la que había dos mujeres con el cargo de secretarias de Estado, sentadas una al lado de la otra, refiriendo los resultados de una reunión bilateral. Los interlocutores de Albright, y seguramente también de Green, siempre habían sido varones.

\section{CONSIDERACIONES FINALES}

La carrera diplomática en nuestros días requiere de funcionarios, mujeres y hombres que sepan interpretar los grandes cambios en el mundo y puedan sacar provecho de éstos para el beneficio de sus países. Es necesario que construyan cada día nuevas relaciones sobre las bases del respeto, la convivencia armónica y el desarrollo equitativo, sin importar religiones, culturas, raza o sexo.

Sin embargo, como se reseña en el presente ensayo, el acceso de las mujeres a la carrera diplomática ha estado lleno de obstáculos, primero de orden legal y luego de carácter social, económico y cultural, impidiendo que, aún en nuestros días, podamos competir en igualdad de circunstancias en ésta y en otras profesiones.

La mujer se ha visto obligada a trabajar con mayor esfuerzo que los varones en la mayoría de los casos para demostrar que sus méritos y trabajo son igualmente valiosos para la administración pública y para el SEM. Por fortuna, este trabajo se ha hecho por mujeres talentosas y ejemplares que abrieron brecha y siguen apoyando la equidad de oportunidades para ambos sexos, demostrando que para ser un buen diplomático no se requiere ser hombre o mujer, sino tener vocación, capacidad y orgullo por trabajar al servicio de la nación.

Queremos cerrar este ensayo con una cita de la primera embajadora de carrera mexicana, Paula Alegría: 
Las mujeres podemos desempeñar bien muchas actividades y podemos equivocarnos exactamente lo mismo que los hombres. Esto sucede en la diplomacia. Puede haber personas de nuestro sexo que descuellen en este terreno y puede haber otras que no tengan capacidad para ello. En todo caso, no se deberá al hecho de ser mujeres, sino a sus dotes individuales y a todos estos factores que influyen en la vida y el trabajo de cualquier persona.

Hay profesiones que sí son específicamente recomendables para nosotras, por razones naturales: las que se relacionan con la infancia o las que tienen algo que ver con el gobierno del hogar, pero en la diplomacia, la distinción de los sexos no es determinante. ${ }^{20}$

\section{ANEXOS}

Anexo I. Secretaría de Relaciones Exteriores. Funcionarias con nivel de mando superior, 1993

- Cardero García, María Elena. Coordinadora de Asuntos Económicos

- Diéguez Armas, Margarita. Directora General de Organismos

- Kovacs Strumpfner, Karen Elizabeth. Director General del Acervo Histórico Diplomático

- Green Macías, María del Rosario. Subsecretaria General Adjunta para Asuntos Políticos de la ONU

- Fuentes-Verain Villenaeva, Sandra. Embajadora en Canadá

- Moreno Toscano, Carmen. Embajadora en Costa Rica

- Paredes Rangel, Beatriz Elena. Embajadora en Cuba

Anexo II. Porcentaje de mujeres en el personal de mandos medios y superiores por secretarías de Estado, 2003

- Presidencia: $40 \%$

- PGR: $29 \%$

- SRE: $43 \%$

- Sagarpa: $16 \%$

20 "Situación privilegiada de México en la Conferencia del Desarme en Ginebra", Novedades, México, D. F., 2 de septiembre de 1962. 
- SCT: $17 \%$

- Sedesol: $30 \%$

- SE: $37 \%$

- SEP: $37 \%$

- Sener: $28 \%$

- SHCP: $33 \%$

- Sedena: $6 \%$

- SRA: $23 \%$

- SM: $6 \%$

- Semarnat: $32 \%$

- SSA: $36 \%$

- SSP: $25 \%$

- Sectur: $30 \%$

- STPS: $29 \%$

- Segob: $30 \%$

- SFP: $35 \%$ 